\title{
INTERVENSI PARTISIPATORI ERGONOMI MENURUNKAN KELELAHAN MELALUI REDESAIN LADLE-KOWI
}

\author{
Ergonomic Participatory Intervention Decreasing Fatigue \\ by Redesigning Ladle-Kowi
}

\author{
Wahyu Susihono ${ }^{1}$, N Adiputra ${ }^{2}$, K Tirtayasa ${ }^{2}$, I.D.P Sutjana ${ }^{2}$ \\ ${ }^{1}$ Jurusan Teknik Industri, Fakultas Teknik, Universitas Sultan Ageng Tirtayasa \\ ${ }^{2}$ Ergonomi Fisiologi Kerja, Program Studi Ilmu Kedokteran, Universitas Udayana \\ (pmy_wahyu@yahoo.co.id)
}

\begin{abstract}
ABSTRAK
Ladel-kowi merupakan alat transportasi manual baja cair suhu 900-1200 C. Ditemukan sikap kerja yang tidak alamiah saat mengoperasikan Ladle-kowi, terdapat gerakan kerja tidak nyaman yang disebabkan desain alat bantu kerja tidak memperhatikan kaidah ergonomi, sehingga timbul kelelahan berlebih. Pajanan suhu lingkungan yang tinggi berpengaruh terhadap aktivitas kerja, motivasi dan kondisi fisik karyawan. Tujuan penelitian ini adalah redesain Ladle-kowi berbasis intervensi partisipatori ergonomi untuk menurunkan kelelahan pekerja di industri pengecoran logam. Penelitian ini merupakan penelitian eksperimental treatment by subject design. Subjek dipilih secara random sampling. Sampel berjumlah 62 orang yang telah memenuhi kriteria inklusi dan eksklusi. Redesain Ladle-Kowi berdasarkan data antropometri pekerja setempat. Skor kelelahan didata dengan 30 items of rating scale yang dikeluarkan oleh Japan Associatin of Industrial an Health. Hasil penelitian menunjukkan bahwa terdapat penurunan secara bermakna antara rerata skor kelelahan subjek pada P1 dengan P2 (nilai p $<0,05$ ). Rerata skor kelelahan sebelum intervensi partisipatori ergonomi 112,61 $\pm 3,84$ dan setelah intervensi partisipatori ergonomi $89,07 \pm 1,70$ atau turun sebesar $12,91 \%$. Penurunan kelelahan pada aspek aktivitas $11,55 \%$, motivasi $10,69 \%$, fisik $16,36 \%$, sedangkan skor penurunan kelelahan secara beturut-turut berdasarkan hari kerja adalah Senin 12,26\%, Selasa 11,39\%, Rabu 13,71\% dan Kamis 14,23\%.
\end{abstract}

Kata kunci : Partisipatori ergonomi, kelelahan, ladle-kowi

\section{ABSTRACT}

Ladel-Kowi is a manual transportation of liquid steel with $900-1200^{\circ} \mathrm{C}$ temperature. Unnatural working posture was revealed while operating Ladle-kowi, there was uncomfortable working movement caused by working tools design that had not been considered ergonomic rules. The exposure of high environment temperature would affect to working activities, motivation, and physical condition of workers. The objective of this research is to redesign ladle-kowi based on ergonomic participatory intervention in order to decrease fatigue of workers in metal molding industry. This research is an experimental research-treatment by subject design. Subjects are chosen by random sampling method. Total of samples is 62 workers that have meet the criteria of inclusion and exclusion. Redesign of ladle-kowi based on anthropometry data of local workers. Fatigues scores collected by 30 items of rating scales published by Japan Association of Industrial an Health. Result showed that there was significant decrease between average score of subject fatigue in $P 1$ and $P 2$ ( $p$ value $<0.05$ ). Average score of fatigue before ergonomic participatory intervention was 112,61 $\pm 3,84$ and after ergonomic participatory intervention was $89.07 \pm 1.70$, or decrease by $12.91 \%$. The decrease of fatigue in activity aspect was $11.55 \%$, motivation was $10.69 \%$, and physic was $16.36 \%$. While score of fatigue decrease consecutively based on weekdays was Monday $12.26 \%$, Tuesday $11.39 \%$, Wednesday $13.71 \%$ and Thursday $14.23 \%$.

Keywords : Ergonomic parcipatory, fatigue, ladle-kowi 


\section{PENDAHULUAN}

Salah satu industri yang mempunyai risiko pencemaran lingkungan tinggi adalah industri pengecoran logam. ${ }^{1,2}$ Dampak yang terjadi akibat aktivitas pada industri ini adalah menurunnya tingkat kesehatan pekerja dan masyarakat yang ada di sekitar industri. Terlebih lagi industri yang keberadaannya pada wilayah pemukiman penduduk, sebagaimana pada industri warisan logam yang ada di wilayah Ceper Klaten, berpotensi dapat menimbulkan pencemaran lingkungan berupa peningkatan nilai kritis ambang batas. Diperlukan pengelolaan lingkungan yang memperhatikan aspek manusia. ${ }^{3,4}$

Salah satu sumber sekunder pencemaran lingkungan adalah pada aktivitas menuang baja cair yang memiliki tingkat kegagalan produk yang cukup tinggi, pengulangan proses pencetakan menyebabkan debu fly ash yang terbentuk meningkat. Terdapat beberapa kejadian pekerja mengalami sesak nafas dan pusing setelah aktivitas menuang baja cair ke dalam cetakan selesai dilakukan. ${ }^{5}$ Kondisi ini terjadi karena suplai $\mathrm{O}_{2}$ dalam darah mengalami penurunan, sistem cardiovaskular tubuh mengalami ketidakseimbangan. Alasan lain karena radiasi panas baja cair menyebabkan nyeri pada tubuh tertentu. ${ }^{6}$ Dampak lain yang timbul adalah pekerja mengalami kelelahan dini. Kondisi ini terjadi karena penurunan tingkat ketahanan tubuh, konsentrasi kerja dan konsumsi energi tubuh berlebih serta penggunaan otot tubuh saat bekerja tidak alamiah, terjadi penumpukan asam laktat. Kadar asam laktat yang tinggi akan memberikan dampak negatif karena akan mempercepat kelelahan. ${ }^{7}$ Ditambah dengan tidak adanya alat bantu kerja yang didesain dengan memperhatikan antropometri manusia untuk memberikan jaminan kenyamanana dan keamanan kerja.

Desain alat bantu kerja pada umumnya tidak melibatkan pengguna, sehingga keinginan dan harapan pengguna sering diabaikan, kenyataan di lapangan muncul pekerja harus menyesuaikan desain alat yang sudah terhadap diri pekerja (fitting the man to the job), padahal manusialah yang seharusnya menjadi human center design. Berbagai fasilitas kerja seharusnya dirancang memperhatikan kemampuan, kebolehan dan kapasitas manusia (fitting the job to the man). Suatu sistem kerja akan berjalan dengan baik bila pekerja memperha- tikan kemampuan dan keterbatasan kondisi fisiologis tubuh pekerja.

Secara umum alat bantu kerja berupa Ladle-kowi yang ada di Industri pengecoran logam, didesain hanya mempertimbangkan fungsinya, belum didesain dengan menggunakan pendekatan ergonomi dan antropometri. Padahal penggunaan antropometri dalam mendesain alat-alat kerja berpengaruh terhadap kesehatan kerja. ${ }^{8}$

Partisipatori ergonomi keterlibatan semua pekerja sejak awal sampai dengan berakhirnya program. Pendekatan partisipatori dalam intervensi ergonomi mampu meningkatkan kualitas hasil pengembangan suatu produk. Pendekatan partisipatori dimulai dari menanyakan langsung pengguna dari beberapa alternatif produk yang digunakan. ${ }^{9}$ Tujuan terhadap adanya redesain Ladle-kowi ini adalah penurunan kelelahan kerja yang disebabkan oleh penggunaan otot secara berlebih, sikap kerja yang tidak alamiah.

Kelelahan muncul karena kehilangan efisiensi, penurunan kapasitas dan ketahanan tubuh. ${ }^{10}$ Kelelahan berdampak pada pekerja di industri pengecoran logam mengalami kelelahan secara fisik ketika muncul perubahan fisiologis yang disebabkan oleh adanya rangsangan secara kontinyu, dan terjadi kelelahan mental atau psikologis ketika terjadi kondisi jiwa yang labil dan terjadi penurunan kinerja. ${ }^{11}$ Tujuan penelitian ini adalah redesain Ladle-kowi berbasis intervensi partisipatori ergonomi untuk menurunkan kelelahan pekerja di industri pengecoran logam.

\section{BAHAN DAN METODE}

Penelitian ini masuk pada kategori penelitian eksperimental dengan menggunakan rancangan sama subjek (treatment by subject design). Subjek dipilih secara random sampling. Jumlah sampel dalam penelitian ini sebanyak 62 orang dan secara keseluruhan jenis kelamin laki-laki. Umur subjek berkisar antara 20-30 tahun dan telah dipilih dan memenuhi kriteria inklusi dan eksklusi. Penelitian ini dilaksanakan di Ceper, Klaten, pada bulan April-Mei 2016. Perlakuan subjek terdiri dari kondisi sebelum intervensi (P1) bekerja menggunakan alat lama atau konvensional, kemudian subjek menjadi kelompok intervensi (P2) menggunakan alat hasil rancangan berbasis partisipatori ergonomi. Pengumpulan data kelelahan 
dengan kuesioner 30 items of rating scale yang dikeluarkan oleh Japan Associatin of Industrial an Health yang terdiri dari tiga kategori; aktivitas melemah (item 1-10), penurunan motivasi (item 11-12), kelelahan fisik (item 21-30) yang dimodifikasi dengan lima skala likert. Pada Periode I pengukuran dilakukan sebelum bekerja (pre-test) dan setelah bekerja (post-test), demikian juga pada Periode II. Uji Normalitas data menggunakan uji Kolmogorov-Smirnov dengan taraf kemaknaan $5 \%$, sedangkan uji efek perlakuan menggunakan uji t-paired, apabila data berdistribusi normal $(\mathrm{p}>0,05)$, apabila data tidak berdistribusi normal
SD 7\% $(n=4)$, pendidikan SMP $14 \%(n=9)$ sedangkan sisanya $79 \%(n=49)$ berpendidikan SMU atau SMK. Hasil pemeriksaan kesehatan menunjukkan bahwa rerata sistole $118,17 \pm 4,24 \mathrm{mmHg}$ sedangkan diastole 76,21 $\pm 5,01 \mathrm{mmHg}$.

Kondisi lingkungan kerja fisik yang diukur meliputi suhu udara, kelembaban, kecepatan angin, intensitas cahaya, kebisingan (Tabel 1). Hasil uji normalitas data kondisi lingkungan kerja antara Periode I dan Periode II menunjukkan bahwa terdapat 3 data tidak berdistribusi normal $(\mathrm{p}<0,05)$ adalah data suhu udara, intensitas cahaya dan kecepatan angin, untuk selanjutnya dilakukan uji Wil-

Tabel 1. Data Kondisi Lingkungan Kerja pada Periode I dan Periode II

\begin{tabular}{|c|c|c|c|c|c|c|}
\hline \multirow{2}{*}{ Variabel } & \multicolumn{2}{|c|}{ Periode I } & \multicolumn{2}{|c|}{ Periode II } & \multirow{2}{*}{ Nilai $t$ atau $z$} & \multirow{2}{*}{ Nilai p } \\
\hline & Rerata & SB & Rerata & SB & & \\
\hline Suhu Udara $\left({ }^{0} \mathrm{C}\right)$ & 30,49 & 2,32 & 30,35 & 3,31 & $-1,817^{\mathrm{z}}$ & $0,069^{\mathrm{b}}$ \\
\hline Kelembaban Relatif (\%) & 78,53 & 4,87 & 77,34 & 2,13 & $1,903^{\mathrm{t}}$ & $0,067^{\mathrm{a}}$ \\
\hline Intensitas Pencahayaan (Lux) & 132,22 & 68,76 & 132,74 & 54,13 & $-0,011^{z}$ & $0,991^{\mathrm{b}}$ \\
\hline Intensitas Kebisingan (dBA) & 67,17 & 3,11 & 67,29 & 2,75 & $-0,263^{t}$ & $0,794^{\mathrm{a}}$ \\
\hline Kecepatan Angin (m/det) & 0,70 & 0,01 & 0,70 & 0,01 & $-0,463^{z}$ & $0,643^{\mathrm{b}}$ \\
\hline
\end{tabular}

Tabel 2. Data Antropometri Tangan Pekerja $(n=62)$

\begin{tabular}{lccccccc}
\hline \multirow{2}{*}{ Data Antropometri } & \multirow{2}{*}{ Rerata } & SB & Min & Max & \multicolumn{3}{c}{ Persentil } \\
\cline { 6 - 8 } & & & & & $\mathbf{5}^{\text {th }}$ & $\mathbf{5 0}^{\text {th }}$ & $\mathbf{9 5}^{\text {th }}$ \\
\hline Panjang Telapak Tangan & 107,36 & 3,84 & 102 & 115 & 101,05 & 107,36 & 113,67 \\
Panjang Jari Kelingking & 57,29 & 3,47 & 53 & 65 & 51,57 & 57,29 & 63,00 \\
Tebal Telapak Tangan Sampai Ibu Jari & 25,43 & 3,20 & 18 & 30 & 20,16 & 25,43 & 30,70 \\
Diameter Genggaman max & 37,79 & 5,16 & 30 & 46 & 29,29 & 37,79 & 46,28 \\
Lebar maksimum Ibu jari ke kelingking & 196,07 & 23,52 & 119 & 215 & 157,38 & 196,07 & 234,76 \\
Lebar Fungsi Maksimum & 139,86 & 15,29 & 116 & 170 & 114,71 & 139,86 & 165,00 \\
Segi-4 mak dapat dilewati Telapak Tangan & 97,50 & 5,36 & 87 & 107 & 88,68 & 97,50 & 106,32 \\
\hline
\end{tabular}

dilakukan transformasi data, apabila data tetap tidak normal dilakukan uji non parametrik Wilcoxon sign ranks test. Pengambilan data P1 dan P2 selama empat kali pengulangan dan Washing Out Period selama 2 hari, adaptasi alat baru selama tiga hari.

\section{HASIL}

Subjek penelitian berjumlah 62 orang semuanya berjenis kelamin laki-laki dengan rerata umur $35,80 \pm 4,18$ tahun, rerata berat badan $63,53 \pm 4,15 \mathrm{~kg}$ dan tinggi badan $164,79 \pm 5,73 \mathrm{~cm}$, IMT $22,97 \pm 3,47 \mathrm{~kg} / \mathrm{m}^{2}$, pengalaman kerja 18,17 $\pm 9,18$ tahun. Latar belakang lulusan pendidikan coxon sign ranks test, hasil uji menunjukkan bahwa $p>0,05$ artinya tidak ada perbedaan bermakna suhu udara, intensitas cahaya dan kecepatan angin pada Periode I dengan Periode II. Data yang berdistribusi normal $(\mathrm{p}>0,05)$ yakni data kelembaban dan kebisingan selanjutnya dilakukan uji t-paired, hasil uji menunjukkan bahwa $p>0,05$ artinya tidak ada perbedaan bermakna kelembaban dan intensitas kebisingan pada Periode I dengan Periode II (Tabel 1). Pengambilan data pada Periode I dan Periode II dilaksanakan dalam lingkungan kerja yang sama. Penurunan kelelahan karyawan disebabkan oleh intervensi partisipatori ergonomi melalui redesain Ladle-kowi. 
Tabel 3. Penurunan Kelelahan

\begin{tabular}{|c|c|c|c|c|c|c|c|c|c|}
\hline Kelelahan yang Dirasakan & $\mathbf{T T}^{\mathbf{a}}$ & $\mathbf{A T}^{\mathbf{a}}$ & $\mathbf{T}^{\mathbf{a}}$ & $\mathbf{S T}^{\mathrm{a}}$ & $\mathbf{S T T}^{\mathrm{b}}$ & $\mathbf{T T}^{\mathrm{b}}$ & $\mathbf{A} \mathbf{T}^{\mathbf{b}}$ & $\mathbf{T}^{\mathbf{b}}$ & $\begin{array}{c}\text { Penurunan } \\
(\%)\end{array}$ \\
\hline \multicolumn{10}{|l|}{ Aspek Aktivitas } \\
\hline Berat bagian kepala & 12,50 & 30,36 & 30,36 & 26,79 & - & 21,43 & 55,36 & 23,21 & 8,94 \\
\hline Lelah seluruh badan & - & 46,43 & 28,57 & 25,00 & 1,79 & 16,07 & 62,50 & 19,64 & 17,86 \\
\hline Kaki terasa berat & 1,79 & 44,64 & 37,50 & 16,07 & - & 12,50 & 30,36 & 57,14 & 10,71 \\
\hline Sering menguap & 3,57 & 17,86 & 53,57 & 25,00 & 1,79 & 10,71 & 7,14 & 80,36 & 8,93 \\
\hline Pikiran terasa kacau & 10,71 & 33,93 & 37,50 & 17,86 & - & 14,29 & 16,07 & 69,64 & 3,58 \\
\hline Merasa mengantuk & 5,36 & 25,00 & 50,00 & 19,64 & - & 32,14 & 28,57 & 39,29 & 26,78 \\
\hline Ada beban pada mata & 14,29 & 33,93 & 25,00 & 26,79 & 1,79 & 17,86 & 30,36 & 50,00 & 5,36 \\
\hline Merasa kaku bergerak & 10,71 & 25,00 & 37,50 & 26,79 & - & 16,07 & 25,00 & 58,93 & 5,36 \\
\hline $\begin{array}{l}\text { Merasa sempoyongan } \\
\text { ketika berdiri }\end{array}$ & 1,79 & 39,29 & 26,79 & 32,14 & 1,79 & 12,50 & 25,00 & 60,71 & 12,51 \\
\hline Perasaan ingin berbaring & 3,57 & 42,86 & 37,50 & 16,07 & - & 16,07 & 28,57 & 55,36 & 12,5 \\
\hline \multicolumn{10}{|l|}{ Aspek Motivas } \\
\hline Merasa susah berfikir & 1,79 & 39,29 & 32,14 & 26,79 & & 26,79 & 46,43 & 26,79 & 25 \\
\hline Merasa lelah bicara & 1,79 & 60,71 & 23,21 & 14,29 & & 14,29 & 25,00 & 60,71 & 12,5 \\
\hline Merasa gugup & - & 46,43 & 35,71 & 17,86 & & 5,36 & 50,00 & 44,64 & 5,36 \\
\hline Tidak bisa berkosentrasi & 5,36 & 41,07 & 33,93 & 19,64 & & 5,36 & 50,00 & 44,64 & 0 \\
\hline $\begin{array}{l}\text { Merasa tidak dapat } \\
\text { memusatkan perhatian }\end{array}$ & - & 17,86 & 46,43 & 35,71 & & 10,71 & 51,79 & 37,50 & 10,71 \\
\hline Kecenderungan lupa & 7,14 & 37,50 & 37,50 & 17,86 & & 8,93 & 50,00 & 41,07 & 1,79 \\
\hline Kurang percaya diri & 5,36 & 39,29 & 39,29 & 16,07 & & 14,29 & 30,36 & 55,36 & 8,93 \\
\hline Merasa cemas & 3,57 & 53,57 & 33,93 & 8,93 & & 12,50 & 60,71 & 26,79 & 8,93 \\
\hline $\begin{array}{l}\text { Tidak dapat mengontrol } \\
\text { sikap }\end{array}$ & 7,14 & 44,64 & 35,71 & 12,50 & & 12,50 & 46,43 & 41,07 & 5,35 \\
\hline $\begin{array}{l}\text { Merasa tidak dapat } \\
\text { tekun dalam pekerjaan }\end{array}$ & 7,14 & 58,93 & 28,57 & 5,36 & & 28,57 & 44,64 & 26,79 & 21,43 \\
\hline \multicolumn{10}{|l|}{ Aspek Fisik } \\
\hline Merasa sakit kepala & 5,36 & 50,00 & 25,00 & 19,64 & 1,79 & 26,79 & 33,93 & 37,50 & 23,21 \\
\hline $\begin{array}{l}\text { Merasa kaku bagian } \\
\text { bahu }\end{array}$ & - & 50,00 & 33,93 & 16,07 & - & 10,71 & 53,57 & 35,71 & 10,72 \\
\hline $\begin{array}{l}\text { Merasa nyeri di } \\
\text { punggung }\end{array}$ & 1,79 & 42,86 & 21,43 & 33,93 & - & 14,29 & 60,71 & 25,00 & 12,51 \\
\hline Nafas merasa tertekan & - & 21,43 & 39,29 & 39,29 & - & 16,07 & 35,71 & 48,21 & 16,09 \\
\hline Merasa haus & 3,57 & 37,50 & 32,14 & 26,79 & - & 7,14 & 44,64 & 48,21 & 3,58 \\
\hline Suara terasa serak & 3,57 & 28,57 & 46,43 & 21,43 & - & 10,71 & 37,50 & 51,79 & 7,14 \\
\hline Merasa pening & 1,79 & 35,71 & 37,50 & 25,00 & - & 26,79 & 37,50 & 35,71 & 25 \\
\hline $\begin{array}{l}\text { Kelopak mata terasa } \\
\text { kejang/kaku }\end{array}$ & 12,50 & 33,93 & 23,21 & 30,36 & - & 25,00 & 28,57 & 46,43 & 12,5 \\
\hline $\begin{array}{l}\text { Anggota badan terasa } \\
\text { bergetar (tremor) }\end{array}$ & 1,79 & 23,21 & 33,93 & 41,07 & - & 19,64 & 37,50 & 42,86 & 17,85 \\
\hline Merasa kurang sehat & 3,57 & 44,64 & 30,36 & 21,43 & - & 35,71 & 28,57 & 35,71 & 32,15 \\
\hline
\end{tabular}

Keterangan : a=Periode I, b=Periode II, STT=Sangat Tidak Terasa, TT=Tidak Terasa, AT=Agak Terasa, T=Terasa, ST $=$ Sangat Terasa

Data antropometri tangan diperlukan untuk mendapatkan data ukuran yang sesuai dengan persentil tangan pekerja. Desain dan Ladle mengacu kepada ukuran antropometri tangan pekerja dengan harapan kenyamanan dan keamanan pengoperasian alat dapat tercapai. Data antropometri tangan pekerja di industri pengecoran logam stasiun pencetakan (Tabel 2) digunakan untuk dasar pembuatan redesain Ladle-kowi (Gambar 1). Data antropometri diameter genggaman $46,28\left(95^{\text {th }}\right)$, panjang telapak tangan $101,05\left(5^{\text {th }}\right)$. Tebal telapak tangan $20,16\left(5^{\text {th }}\right)$ lebar maksimum ibu jari 157,38 
$\left(5^{\text {th }}\right)$ segi-4 maksimum dilewati telapak tangan $\left(88,68\left(5^{\text {th }}\right)\right.$ dan panjang jari ke kelingking 51,57 $\left(5^{\text {th }}\right)$ digunakan sebagai dasar redesain busa, sedangkan pemberat rangka tameng menggunakan batas angkat maksimum pekerja. Penempatan tameng menggunakan sudut pandangan mata melihat titik pusat Ladle-kowi.

Kuesioner pengukuran data kelelahan subjektif menggunakan kuesioner 30 Items of Rating Scale sebelum dan setelah aktivitas kerja telah diuji validitas dengan hasil menunjukkan semua butir valid ( $\mathrm{r}$ hitung $>\mathrm{r}$ tabel), tabel $\mathrm{r}$ pada $\alpha=5 \%$ adalah 0,458 atau signifikansi $<0,05$ sedangkan reliabilitas kuesioner diperoleh nilai Cronbach's Alpha $=0,757$ (di atas 0,6). Kelelahan sebelum aktivitas Periode I dan II serta kelelahan setelah aktivitas Periode II menunjukkan bahwa ke tiga data berdistribusi normal $(p>0,05)$ sedangkan hasil uji normalitas pada kelelahan setelah aktivitas Periode I data tidak berdistribusi normal $(\mathrm{p}<0,05)$. Analisis kemaknaan dengan uji Wilcoxon sign ranks test menunjukkan bahwa rerata kelelahan sebelum aktivitas pada ke dua periode tidak berbeda bermakna ( $>00,05)$, kondisi awal subjek sama, rerata skor kelelahan sebelum aktivitas pada Periode I dan Periode II sama. Uji efek perlakuan berdasarkan rerata skor kelelahan setelah aktivitas antara Periode I dan Periode II menunjukkan bahwa rerata kelelahan pada ke dua periode berbeda bermakna $(p<0,05)$. Nilai ini menunjukkan bahwa penggunaan alat Ladle-kowi hasil rancangan mampu menurukan kelelahan pekerja.

Kelelahan kerja dibagi menjadi tigas aspek yang secara keseluruhan telah dikembangkan oleh Japan Associatin of Industrial an Health. Penurunan kelelahan pada ketiga aspek adalah pada aktivitas $11,55 \%$, motivasi $10,69 \%$ dan fisik $16,36 \%$ (Gambar 2). Terjadi perubahan tingkat kelelahan pekerja sebelum intervensi ergonomi pada Periode I dengan setelah intervensi ergonomi pada Periode II. Penurunan skor kelelahan secara beturut-turut berdasarkan hari kerja adalah senin $12,26 \%$, selasa $11,39 \%$, rabu $13,71 \%$ dan kamis $14,23 \%$ (Gambar 2).

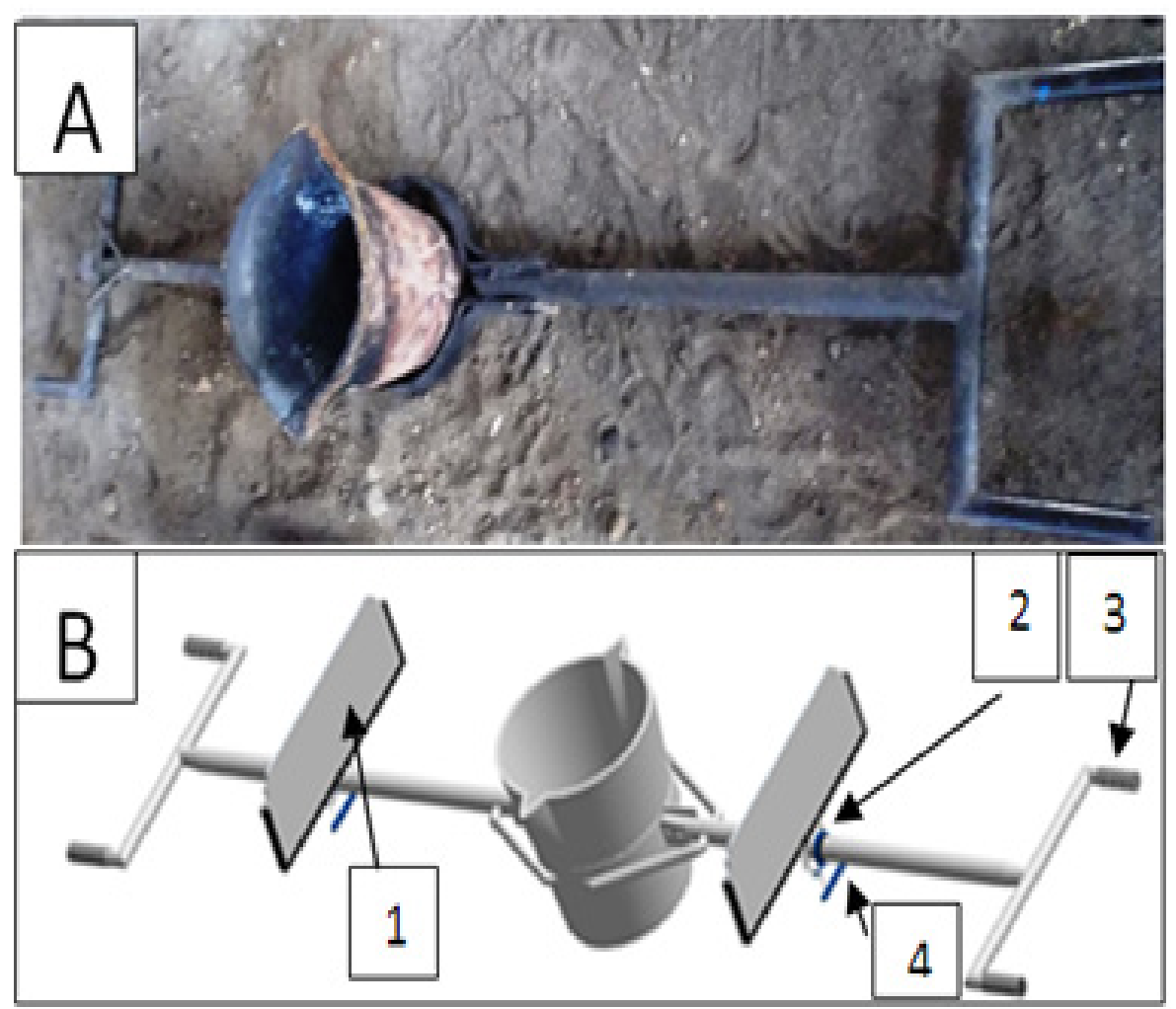

Gambar. 1: Ladle-Kowi konvensional, B: Ladle-Kowi Redesain dengan Penambahan 1:Tameng Akrilik, 2:Laker, 3: poros AS, 3: busa, 4: pemberat rangka tameng 


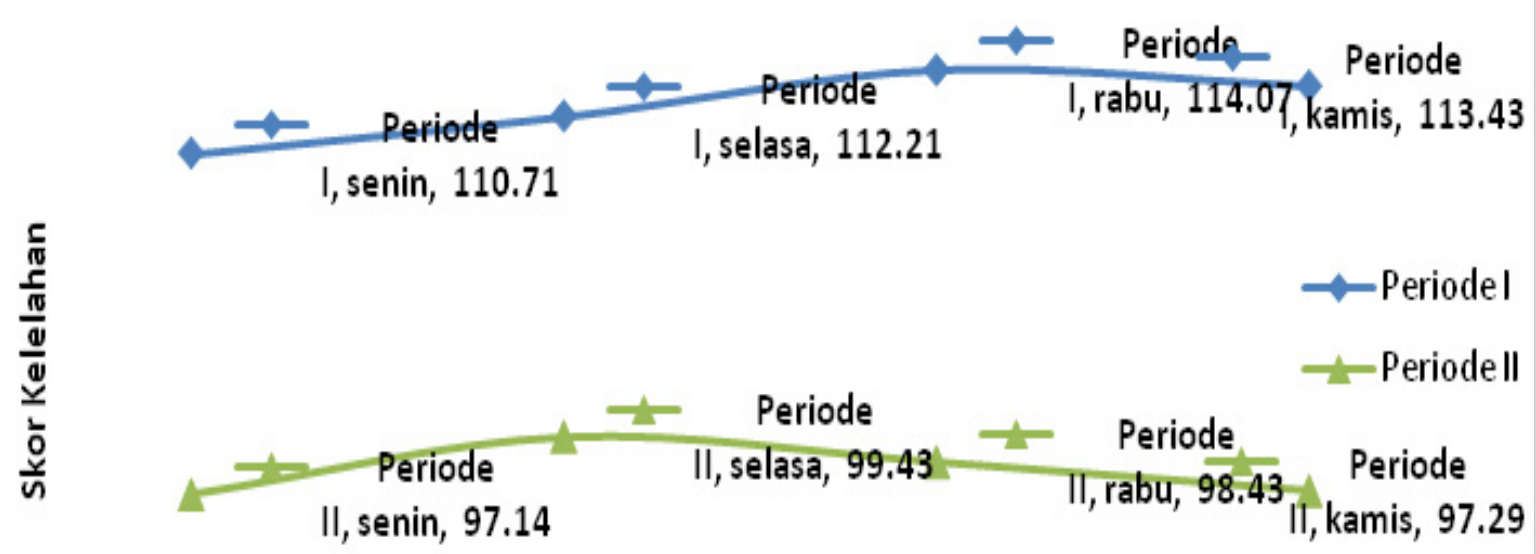

Harike-

\section{Gambar 2. Perbedaan Skor Kelelahan Berdasarkan Hari Kerja P1 dan P2}

\section{PEMBAHASAN}

Menurut UU No. 13 tahun 2003 Bab I pasal 1 ayat 2 disebutkan bahwa tenaga kerja adalah setiap orang yang mampu melakukan pekerjaan guna menghasilkan barang dan atau jasa untuk memenuhi kebutuhan sendiri maupun untuk masyarakat. Batas usia kerja yang berlaku di Indonesia adalah berumur 15 sampai dengan 64 tahun. Namun demikian, umur subjek pada penelitian ini bila dilihat dari kekuatan otot sudah mengalami penurunan untuk bekerja, karena umur optimal yang dianjurkan antara $20 \mathrm{~s} / \mathrm{d} 30$ tahun. ${ }^{12}$ Kekuatan otot berada pada rentang umur 25 sampai dengan 35 tahun. ${ }^{13}$ Rerata pengalaman kerja subjek sebesar 18,14 $\pm 9,18$ tahun, menunjukkan bahwa pekerja telah terampil dan mampu beradaptasi dengan pekerjaannya. Pengalaman kerja dan latar belakang pendidikan mempunyai hubungan yang sangat erat dalam aktivitas subjek untuk menyelesaikan pekerjaanya.

Hasil pengukuran berat badan dan tinggi badan digunakan sebagai dasar untuk menghitung rerata Indeks Massa Tubuh (IMT). Subjek pada penelitian ini mempunyai rerata IMT sebesar 22,97 $\pm 3,47 \mathrm{~kg} / \mathrm{m}^{2}$. Nilai IMT ini memberi informasi bahwa pekerja berada dalam kondisi status gizi normal, berada pada kisaran antara 18,5 sampai dengan $25,0 \mathrm{~kg} / \mathrm{m}^{2}$. IMT normal orang indonesia berkisar pada nilai $18,5-25 \mathrm{~kg} / \mathrm{m}^{2}$. IMT mencerminkan keseimbangan asupan gizi seseorang dan dapat menurun bila asupan gizi berkurang secara berkelanjutan. ${ }^{14}$ Kelebihan maupun kekurangan berat badan berpengaruh terhadap kondisi kesehatan kerja dan metabolisme tubuh.

Nilai rerata tekanan darah sistolik pekerja sebesar $118,17 \pm 4,24 \mathrm{mmHg}$ sedangkan rerata tekanan darah diastolik sebesar 76,21 $\pm 5,01 \mathrm{mmHg}$ menunjukkan bahwa subjek berada dalam kondisi sehat dan dapat bekerja, sehingga dapat digunakan sebagai sampel dalam penelitian ini. Tekanan da-rah dikategorikan optimal bila tekanan darah sistolik $<120 \mathrm{mmHg}$ dan tekanan darah diastolik $<80 \mathrm{mmHg}$ dan dikatakan normal apabila tekanan darah sistolik $130 \mathrm{mmHg}$ dan tekanan darah diastolik $<85 \mathrm{mmHg}$. Tekanan darah optimal adalah apabila tekanan darah sistolik $<120 \mathrm{mmHg}$ dan diastolik $<80 \mathrm{mmHg}$, tekanan darah normal apabila tekanan darah sistolik $<130 \mathrm{mmHg}$ dan diastolik $<85 \mathrm{mmHg}$, tekanan darah normal-tinggi apabila tekanan darah sistolik $130-139 \mathrm{mmHg}$ dan diasto- 
lik $85-89 \mathrm{mmHg}$, tekanan darah hipertensi derajat 1 apabila tekanan darah sistolik $140-159 \mathrm{mmHg}$ dan diastolik $90-99$ mmHg. ${ }^{15}$

Subjek merasa nyaman dengan kondisi lingkungan kerja yang ada pada saat ini, alasan ini dikuatkan bahwa kondisi lingkungan berupa suhu udara, kelembaban relatif, intensitas cahaya, intensitas kebisingan dan kecepatan angin masih berada di bawah Nilai Ambang Batas (NAB) yang dipersyaratkan di negara Indonesia. Lingkungan kerja dalam kondisi terlalu panas menyebabkan rasa kantuk dan lelah, menurunnya ketrampilan dan meningkatnya kemungkinan membuat kesalahan, tetapi sebaliknya apabila lingkungan terlalu dingin merangsang munculnya perasaan tidak tenang, terganggu konsentrasi kerja. ${ }^{16}$ Kondisi lembab dapat menyebabkan keringat tidak dapat berevaporasi, sedangkan kelembaban yang terlalu tinggi disertai dengan temperatur lingkungan yang tinggi dapat meningkatkan denyut jantung, mempercepat terjadinya penguapan keringat yang berdampak pekerja akan merasa haus dan cepat mengalami kelelahan. Beda rerata kelembaban menunjukkan bahwa nilai $(p>0,05)$ artinya kelembaban pada penelitian Periode I dan Periode II dilaksanakan dalam lingkungan yang sama, sehingga faktor kelembaban yang akan memengaruhi intervensi tidak ada. Nilai kelembaban relatif pada penelitian ini berada pada kondisi aman untuk bekerja, sesuai keputusan Menkes RI No. 405 tahun 2002 tentang persyaratan dan tata cara penyelenggaraan kesehatan lingkungan kerja industri, kelembaban berada pada kisaran 65\%-95\%. Beda rerata intensitas cahaya mempunyai nilai $p>0,05$ artinya intensitas cahaya pada penelitian dilaksanakan dalam lingkungan yang sama, sehingga intensitas cahaya yang akan mempengaruhi intervensi tidak ada. Keputusan Menkes RI No 405 tahun 2002 tentang persyaratan dan tata cara penyelenggaraan kesehatan lingkungan kerja industri, untuk pekerjaan kasar membutuhkan minimal intensitas cahaya sebesar 100 lux. Pencahayaan yang tidak cukup atau dibawah ambang batas yang dipersyaratkan akan menimbulkan kelelahan kerja. Kurangnya intensitas cahaya ditempat kerja berakibat penurunan penglihatan mata dan kelelahan kerja. ${ }^{17}$

Kondisi bising adalah semua suara yang tidak dikehendaki yang bersumber dari alat-alat proses produksi dan atau alat kerja yang pada tingkat tertentu dapat menimbulkan gangguan pendengaran. Bising yang berada di atas nilai ambang batas dapat memicu perubahan kardiovaskuler dalam tubuh pekerja. Peraturan Menakertrans RI No 13 tahun 2011, tentang NAB Faktor Fisika dan Kimia di Tempat Kerja, intensitas bising tidak boleh melebihi 85 dBA pada waktu pemaparan perhari selama 8 jam. Kebisingan tempat kerja masih pada batas normal bila berada dibawah 85 dBA. ${ }^{18}$ Kecepatan angin adalah udara yang bergerak atau mengalir secara horizontal pada ketinggian dua meter di atas tanah. Angin yang ada di industri pengecoran logam berhembus dari pintu ke pintu atau dari lubang angin yang berada di antara atap dengan dinding pabrik. Pada penelitian ini kecepatan angin pada kedua periode dilaksanakan dalam lingkungan yang sama. Dianjurkan gerakan udara di dalam ruangan tidak lebih dari $0,2 \mathrm{~m} / \mathrm{s}$ agar gerakan udara tidak menimbulkan dampak buruk terhadap pekerja. ${ }^{19}$ Namun demikian, aktivitas lingkungan yang panas dibutuhkan intensitas kecepatan angin yang relatif lebih tinggi. ${ }^{20}$

Data antropometri yang digunakan untuk redesain Ladle-kowi. Data antropometri sebagai dasar rancangan produk atau desain produk. ${ }^{21}$ Penggunaan data antropometri pada redesain komponen Ladle-kowi menggunakan persentil $5^{\text {th }}$ mempunyai arti bahwa ukuran yang berada dibawah rata-rata masih dapat menggunakan produk hasil rancangan. Data antropometri dengan pilihan persentil $95^{\text {th }}$ mempunyai arti bahwa $95 \%$ komponen redesain produk mempunyai ukuran lebih panjang dibanding ukuran rerata. Penyesuaian data antropometri mengacu pada persentil $5^{\text {th }}$ dan persentil $95^{\text {th }}$ dapat mengoptimalkan desain yang akan dirancang. ${ }^{22}$ Penentuan dimensi pengukuran tangan dilakukan pada subjek secara langsung agar rancangan produk sesuai dengan data antropometri aktual. ${ }^{23}$ Data antropometri pada setiap negara berbeda-beda, sehingga setiap redesain produk diperlukan data antropometri pekerja setempat. ${ }^{24,25}$ Berkembangnya usia suatu negara maka data antropometri juga mengalami perubahan. ${ }^{26}$ Data antropometri dapat digunakan untuk penilaian kesehatan dan keselamatan kerja guna mengurangi kejadian cidera dan penyakit kerja di sektor manufaktur. ${ }^{27}$ Ladle-kowi baru berdampak pada perubahan Standar Operasional Prosedur 
(SOP) pengoperasian alat, mulai dari sikap kerja memegang Ladle-kowi sampai sikap kerja penuangan baja cair ke dalam cetakan sehingga berpengaruh terhadap perubahan lain seperti penurunan kelelahan kerja.

Kelelahan adalah suatu mekanisme perlindungan tubuh agar pekerja segera beristirahat yang disebabkan karena penurunan efisiensi, kapasitas kerja dan ketahanan tubuh. Kelelahan merupakan penurunan kinerja fisik maupun mental. ${ }^{28}$ Perbaikan SOP turut serta memberikan pengaruh terhadap perubahan kelelahan pekerja. Keluhan subyektif disebabkan sikap kerja yang kurang alamiah dan kondisi lingkungan kerja yang tidak sehat yang timbul akibat sikap kerja dan fasilitas kerja yang tidak ergonomi. Standar Operasional Prosedur (SOP) memberikan kemudahan dalam pengoperasian alat dan meminimalisir timbulkan kelelahan yang disebabkan oleh postur kerja yang tidak alamiah. Kelelahan otot tungkai bawah secara signifikan dipengaruhi oleh postur tubuh saat bekerja. Postur kerja jongkok dan berlutut menyumbang keluhan paling tinggi dibandingkan postur kerja berdiri atau duduk yang ditunjukkan dengan perubahan detak jantung seseorang saat bekerja. $^{29}$

Kelelahan dapat diuraikan menjadi tiga kate-gori yakni aktivitas pelemahan kerja, penurunan motivasi dan kelelahan fisik. Berdasarkan hasil uji Wilcoxon sign ranks test menunjukkan bahwa kelelahan sebelum aktivitas dari ketiga aspek, yaitu aktivitas, motivasi dan fisik mempunyai nilai $p>0,05$ artinya kondisi awal subjek pada Periode I dan Periode II adalah sama. Terdapat kecenderungan kelelahan terus meningkat mulai dari awal aktivitas kerja sampai dengan akhir aktivitas kerja dan terjadi kelelahan puncak berada pada akhir shift kerja. ${ }^{30}$ Jika dikaitkan dengan penurunan kelelahan pekerja di stasiun pencetakan cukup beralasan, karena pada Periode II dilakukan intervensi partisipatori ergonomi melalui redesain Ladle-kowi, ini berdampak pada pemulihan tenaga otot pekerja yang semula bekerja dengan otot maksimum, setelah perbaikan menggunakan otot yang disesuaikan dengan kemampuan dan kapasitas pekerja. Kerja dapat dipertahankan dalam beberapa jam per hari tanpa gejala kelelahan jika tenaga yang dikerahkan tidak melebihi $80 \%$ dari maksimum tenaga otot.
Pada penelitian ini, skor rerata kelelahan umum mengalami penurunan $12,91 \%$ yang disebabkan karena intervensi ergonomi partisipatori melalui redesain Ladle-kowi. Penelitian tentang kelelahan kerja pada berbagi industri telah dilakukan oleh penelitian sebelumnya. Hasil ditunjukkan adanya perubahan dengan prosentase lebih rendah dibandingkan dengan hasil pada penelitian ini. ${ }^{31}$ Namun demikian, terdapat beberapa penelitian yang mempunyai perubahan prosentase lebih besar dibanding dengan hasil penelitian ini. ${ }^{32-34}$ Kelelahan pada tiap harinya mengalami perubahan, tetapi trend perubahan yang terjadi berupa garis linier kecenderungan meningkat pada axis (x). Skor kelelahan dari hari senin sampai dengan hari rabu terus mengalami peningkatan, sedangkan di hari kamis mulai turun kecenderungan menurun, sedangkan pada Periode II kecenderungan meningkat mulai hari senin sampai dengan selasa, sedangkan mulai hari rabu mengalami penurunan. Kondisi ini menunjukkan bahwa faktor motivasi mempunyai pengaruh terhadap penurunan kelelahan kerja.

Dampak adanya partisipatori ergonomi telah dirasakan oleh pekerja dalam menelesaikan pekerjaanya. Penurunan kelelahan paling tinggi berada pada hari kamis, kelelahan fisik paling dominan yakni $16,36 \%$ dan kelelahan pada aspek aktivitas $11,55 \%$ menunjukkan bahwa penggunaan redesain Ladle-kowi mampu mengurangi sikap kerja yang tidak alamiah, pekerja lebih efektif dan lebih nyaman menggunakan alat baru. Penurunan kelelahan pada aspek motivasi sebesar $10,69 \%$ menunjukkan bahwa aktivitas partisipatori ergonomi berupa keterlibatan pengguna secara langsung untuk mengakomodir keinginan dan harapan pengguna, desain alat berbasis human center design dan Ladle-kowi dirancang memperhatikan kemampuan, kebolehan dan kapasitas manusia (fitting the job to the man) mampu menurunkan kelelahan kerja secara menyeluruh.

\section{KESIMPULAN DAN SARAN}

Rerata skor kelelahan sebelum intervensi partisipatori ergonomi $112,61 \pm 3,84$ dan setelah intervensi partisipatori ergonomi $89,07 \pm 1,70$ atau turun sebesar $12,91 \%$. Redesain Ladle-kowi melalui intervensi partisipatori ergonomi mampu menurunkan kelelahan kerja sebesar $12,91 \%$. Hasil 
analisis menunjukkan bahwa terdapat penurunan secara bermakna antara rerata skor kelelahan subjek pada P1 dengan P2 (nilai $\mathrm{p}<0,05$ ). Penurunan kelelahan kerja ini disebabkan oleh adanya perbaikan sikap kerja saat menuang baja cair ke dalam cetakan sehingga beban penggunaan otot tubuh lebih alamiah, aktivitas kerja lebih efektif, terjadi peningkatan motivasi kerja yang disebabkan oleh penggunaan Ladle-kowi baru mempertimbangkan keinginan pengguna. Jika dilihat dari tiga kategori, penurunan kelelahan pada aspek aktivitas $11,55 \%$, motivasi $10,69 \%$ dan fisik $16,36 \%$. Penurunan kelelahan pada tiap hari kerja mengalami perubahan, secara beturut-turut senin $12,26 \%$, selasa $11,39 \%$, rabu $13,71 \%$ dan kamis $14,23 \%$. Penurunan kelelahan paling tinggi terjadi pada hari kamis menjelang libur kerja.

Perlu dilakukan penelitian lebih lanjut penerapan intervensi ergonomi pada stasiun kerja lainnya terkait dengan penggunaan manual material handling (MMH) agar kelelahan yang terjadi sebagai akibat dari aktivitas penyelesaian proses kerja dapat diturunkan sesuai dengan keterbatasan, kemampuan dan kebolehan manusia. Agar memperoleh gambaran dampak fisiologis pekerja terhadap penerapan intervensi ergonomi, perlu dilakukan pemeriksaan kelelahan otot perifer secara berkala.

\section{DAFTAR PUSTAKA}

1. Korol, D.B. Life Cycle Assessment of Steel Production in Poland: a Case Study. Journal of Cleaner Production. 2013; 54(54):235-243.

2. Strezov, V. Evans, A. Evans, T. Defining Sustainability Indicators of Iron and Steel Production. Journal of Cleaner Production. 2013; 51(2013):66-70

3. Zink, K.J and Fischer, K. Do We Need Sustainability as A New Approach in Human Factors and Ergonomics. Ergonomics. 2013; 56 (3):348-356.

4. Zink, K.J. Designing Sustainable Work Systems: The Need for a Systems Approach. Applied Ergonomics. 2014: 45(1) :126-132.

5. Susihono, W. Penerapan Teknologi Produksi Bersih Berorientasi Ergonomi Total Meningkatkan Kinerja Karyawan, Kualitas Lingkungan Perusahaan dan Nilai Tambah Limbah Stasiun Pencetakan Logam di Batur Ceper
Klaten [Disertasi]. Denpasar: Program Doktor-Pascasarjana Universitas Udayana; 2016.

6. Kee, D and Karwowski, W. A Comparison of Three Observational Techniques for Assessing Postural Load in Industry. International Journal of Occupational Safety and Ergonomics (JOSE). 2007; 13(1):3-14.

7. Candra, A. Rusip, G. Machrina, Y. Pengaruh Latihan Aerobik terhadap Asam Laktat dan Skala Borg Atlet Sepakbola. Jurnal Media Kesehatan Masyarakat (MKMI). 2016; 12(1):8-12.

8. Dianat, I. Karimi, M.A. Hashemi, A.A. Bahrampour, S. Classroom Furniture and Anthropometric Characteristics of Iranian High School Students: Proposed Dimensions Based on Anthropometric Data. Applied Ergonomics. 2013;44:101-108

9. Vink, P. Ernst A.P. Koningsveld, E.A.P. Molenbroek, J.F. Positive Outcomes of Participatory Ergonomics in Terms of Greater Comfort and Higher Productivity. Applied Ergonomics. 2006; 37(40):537-546.

10. Susetyo, J. Oes, T.I. Indonesiani, S.H. Prevalensi Keluhan Subyektif atau Kelelahan Karena Sikap Kerja yang Tidak Ergonomis pada Pengrajin Perak. Jurnal Teknologi. 2008;1(2): 141-149.

11. Kitamura, H. Shindo, M. Tachibana, A. Honma, H. Sumera, T. Personality and Resilience Association with Perceived Fatigue of Local Government Employees Responding to Disaster. Journal Occupational Health. 2013; 55(1):1-5.

12. Reenan, H,H. Beek, A.J. Blatter, B.M. Mechelen, W.V. Bongers, P.M. Age-Related Differences in Muscular Capacity among Workers. Journal of int Arch Occup Environt Health. 2009; 82(9):1115-1121.

13. Permana, D.R. Wahyuni, I. Perbedaan Nilai Kesegaran Punggung Sebelum dan Sesudah Pemberian Stretching Mc. Kenzie Extension pada Pekerja Wanita Pengepak Jamu PT. X Semarang. Media Kesehatan Masyarakat Indonesia. 2010; 9(1):18-26

14. Adiatmika, I.P.G. Perbaikan Kondisi Kerja dengan Pendekatan Ergonomi Total Menurunkan Keluhan Muskuloskeletal dan Kelelahan serta Meningkatkan Produktivitas dan Penghasilan 
Perajin Pengecatan Logam di Kediri-Tabanan [Disertasi]. Denpasar: Program Pasca Sarjana Universitas Udayana; 2007.

15. Kuswardhani, R.A. Penatalaksanaan Hipertensi pada Lanjut Usia. Journal Penyakit Dalam. 2006; 7(2):135 - 140.

16. Handari, A.L.M.I.S. Ergo-Psikofisiologi Menurunkan Respon Fisiologis, Meningkatkan Kesigapan, Kemampuan Kerja dan Work Engagement Karyawan Bagian Akutansi Hotel Bali Hyatt di Denpasar [Disertasi]. Denpasar: Program Pasca Sarjana Universitas Udayana; 2013.

17. Tarwaka. Ergonomi Industri; Dasar-Dasar Pengetahuan Ergonomi dan Aplikasi di Tempat Kerja. Ed ${ }^{1}$ Cet 1. Solo: Harapan Press; 2010.

18. Kroemer, K.H.E. Workload and Stress. In Fitting the Human, Introduction to Ergonomics. USA: Taylor and Francis; 2009

19. Priambadi, I.G.N. Perbaikan Kondisi Kerja Peleburan Paduan Perunggu Meningkatkan Kinerja Perajin Gamelan Bali di Desa Tihingan Klungkung [Disertasi]. Denpasar: Program Pascasarjana Universitas Udayana; 2012.

20. Setiawan, H. Desain Stasiun Kerja Blanket Basah Berbasis Ergonomi Meningkatkan Kualitas Hidup dan Produktivitas Pekerja di PT Sunan Rubber Palembang Provinsi Sumatera Selatan [Disertasi]. Denpasar: Program Pasca Sarjana Universitas Udayana; 2013.

21. Dewangana, K.N. Owarya, C. Dattab, R.K. Anthropometric Data of Female Farm Workers from North Eastern India and Design of Hand Tools of the Hilly Region. International Journal of Industrial Ergonomics. 2008;38: 90-100.

22. Rafael Guillermo García, C.R.G. Felknor, S. Córdoba, J.E. Caballero, J.P. Barrero, L.H. Hand Anthropometry of the Colombian Floriculture Workers of the Bogota Plateau. International Journal of Industrial Ergonomics. 2012;42:183-198.

23. Kwon, O. Jung, K. Heecheon, You. Hee-Eun K. Determination of Key Dimensions for a Glove Sizing System by Analyzing the Relationships between Hand Dimensions. Applied Ergonomics. 2009;40(4):762-766.
24. Leilanie, D.P.J. Anthropometric Measurement of Filipino Manufacturing Workers. International Journal of Industrial Ergonomics. 2007; 37(6):497-503.

25. Chuan, K.T. Hartono, M. Kumar, N. Anthropometry of the Singaporean and Indonesian Populations. International Journal of Industrial Ergonomics. 2010;40(6):757-766.

26. Hanson, L. Sperling, L. Gunvor, G. Staffan, I. Vergara, C.O. Swedish Anthropometrics for Product and Workplace Design. Applied Ergonomics. 2009;40:797-806.

27. Laios, L. Giannatsis, J.. Ergonomic Evaluation and Redesign of Children Bicycles based on Anthropometric Data. Applied Ergonomics. 2010;41:428-435.

28. Nisa, A.Z dan Martiana, T. Faktor yang Memengaruhi Keluhan Kelelahan pada Teknisi Gigi di Laboratorium Gigi Surabaya. The Indonesian Journal of Occupational Safety and Health. 2013;2(1):61-66.

29. Myung-Chul, J. DongHyun, P. Soo-Jin, L. Kyung-Suk, L. Dae-Min, K. Yong-Ku, K.. The Effects of Knee Angles on Subjective Discomfort Ratings, Heart Rates, and Muscle Fatigue of Lower Extremities in Static-Sustaining Tasks. Applied Ergonomics. 2010;42:184192.

30. Sarah, M.J. Dawson, D. Ferguson, S.A. Lamond. N. Driver Fatigue during Extended Rail Operations. Applied Ergonomics. 2008; 39:623-629.

31. Titin, I.O. Intervensi Ergonomi pada Proses Stamping Part Body Component Meningkatkan Kualitas dan Kepuasan Kerja serta Efisiensi Waktu di Divisi Stamping Plant PT. ADM Jakarta [Disertasi]. Denpasar: Program Pasca Sarjana Universitas Udayana; 2010.

32. Sutajaya, I.M. Pembelajaran melalui Pendekatan Sistemik, Holistik, Interdisipliner dan Partisipatori (SHIP) Mengurangi Kelelahan, Keluhan Muskuloskeletal dan Kebosanan serta Meningkatkan Luaran Proses Belajar Mahasiswa Biologi IKIP Singaraja [Disertasi]. Denpasar: Program Pasca Sarjana Universitas Udayana; 2006.

33. Muliarta, I.M. Perbaikan Kondisi Kerja Komputer Menurunkan Ketegangan Otot, Beban Kerja dan Keluhan Subjektif Mahasiswa De- 
sain Komunikasi Visual Institut Seni Indonesia Denpasar [Disertasi]. Denpasar: Program Pasca Sarjana Universitas Udayana; 2014.

34. Adnyana, I.W.B. Aplikasi Synergi Ergo-Mechanical System Meningkatkan Kapasitas
Kerja Para Pekerja Wanita dan Efisiensi Energi Bahan Bakar Alat Pengering pada Industri Sarana Banten di Blahbatuh Gianjar Bali [Disertasi]. Denpasar: Program Doktor-Pascasarjana Universitas Udayana; 2013. 